\title{
Safety of adhesively bonded joints under detrimental service conditions
}

\author{
Katja Groß ${ }^{*}$ (D) and Paul Ludwig Geiß
}

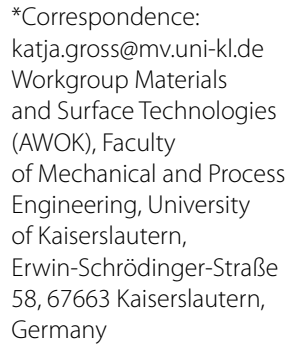

\begin{abstract}
Durability and safety of adhesively bonded joints are of major importance in structural applications. The probability of failure of a bonded assembly after a certain period of time may be influenced by various aging effects including e.g. temperature and humidity. The correlation of results obtained from accelerated laboratory aging tests to long-term aging under service conditions often remains an unsolved challenge. In the present work, computer-based tools for non-linear regression analysis, estimation of reliability and lifetime prediction have been applied to experimental results obtained by accelerated aging of adhesively bonded shear specimens. Results obtained with an epoxy based adhesive and a hot-dipped galvanized steel as adherend are discussed. The modeling of the aging behavior is performed with combined functions referring to the EYRING as well as the PECK model which both appear appropriate for describing the experimental data. The safety prediction, based on the probability of failure as well as the safety factor $\beta$, is performed by using the EYRING model which fits the experimental data in a more conservative manner.
\end{abstract}

Keywords: Adhesively bonded joints, Accelerated aging, Safety, Extrapolation

\section{Introduction}

In recent decades the use of adhesively bonded joints in industrial applications has become increasingly important and is replacing conventional joining techniques in many areas. In order to meet sector-dependent safety requirements the aging behavior of adhesively bonded joints needs to be considered. Hereof, aging is defined as a reduction in strength or safety as a function of time caused by external factors including e.g. mechanical stress, temperature and humidity. However, high number of potentially damaging factors on adhesively bonded joints in industrial applications makes it difficult to perform a reliable lifetime prediction while considering all relevant aging factors. Several models for describing degradation have been discussed in literature [1-8] which allow lifetime predictions as a function of one or two influencing factors, but these models do not consider the statistical variance of experimental data. The aim of this study is to develop a damage function for describing the aging of adhesively bonded joints and prediction of the safety level as a function of the influencing parameters temperature, humidity and load considering the statistical distribution of the experimental data. The development of this function is based on systematic aging studies by combining different models.

(c) The Author(s) 2018. This article is distributed under the terms of the Creative Commons Attribution 4.0 International License (http://creativecommons.org/licenses/by/4.0/), which permits unrestricted use, distribution, and reproduction in any medium, provided you give appropriate credit to the original author(s) and the source, provide a link to the Creative Commons license, and indicate if changes were made. 


\section{Experimental Materials}

In the present work, the single component hot curing epoxy adhesive Betamate ${ }^{\circledR} 1496 \mathrm{~F}$ (Dow Automotive AG, Freienbach, Switzerland) was used to join adherends of hotdipped galvanized dual-phase steel (DP800Z) (Voestalpine Steel GmbH, Linz, Austria). The epoxy adhesive Betamate ${ }^{\circledR} 1496 \mathrm{~F}$ is used in the automotive industry in order to increase the operation durability, the crash performance and the body stiffness [9]. Hotdipped galvanized dual-phase steels are commonly used in automotive engineering in complex structural components due to their excellent crash performance and corrosion resistance [10]. In order to represent typical adhesively bonded joints in industrial applications, the epoxy adhesive Betamate ${ }^{\circledR} 1496 \mathrm{~F}$ is combined with hot-dipped galvanized steel exemplarily. The properties of the adhesive are presented in Table 1 and the properties of the adherends in Table 2.

\section{Specimen manufacturing}

Before adhesive application, the steel surface was degreased by manually wiping with acetone followed by an ultrasonic dip-cleaning using a 1:1-mixture of isopropanol and purified water. After chemical surface cleaning the steel adherends were bonded with an overlap length of $10 \mathrm{~mm}$ and a sample width of $25 \mathrm{~mm}$ using the epoxy adhesive. Since hot-dipped galvanized steel sheets were only available with a limited thickness of $2 \mathrm{~mm}$, laminated shear joints [15] were prepared using spacers adjacent to the test panels while curing in the lamination press. The joint thickness was set to $0.7 \mathrm{~mm}$ and the curing was performed at $180^{\circ} \mathrm{C}$ for $1 \mathrm{~h}$.

\section{Accelerated laboratory aging tests}

In this study accelerated destructive degradation were performed in order to generate an experimental data base for doing a reliable safety prediction for adhesively bonded joints. These tests are used by engineers in the manufacturing industry for many decades in order to acquire reliability information in up-front testing more quickly than in traditional life tests $[2,16]$. The accelerated laboratory aging tests of the adhesively bonded shear specimens in this study were performed at $60{ }^{\circ} \mathrm{C} / 95 \%$ relative humidity (RH) and $80{ }^{\circ} \mathrm{C} / 95 \% \mathrm{RH}$. As reference condition $23{ }^{\circ} \mathrm{C} / 50 \% \mathrm{RH}$ was used. For all conditions

Table 1 Properties of the epoxy adhesive Betamate ${ }^{\circledR} 1496 \mathrm{~F}$

Young's modulus (MPa) at $23^{\circ} \mathrm{C}(\mathrm{ISO} 527-1)$ [11] $\quad 1600$

Maximum tensile strength (MPa) at $23^{\circ} \mathrm{C}$ (ISO 527-1) [11]

Glass transition temperature $\left({ }^{\circ} \mathrm{C}\right)$ at $\tan \delta$ peak, $1 \mathrm{~Hz}$ (ISO 6721-1) [12] 105

Table 2 Properties of the hot-dipped galvanized steel (DP800Z) [10], pursant to EN 10346 [13] and EN 10338 [14]

\begin{tabular}{ll} 
Yield stress (MPa) & $440-550$ \\
Ultimate strength (MPa) & 780 \\
Ultimate strain (\%) & 14 \\
\hline
\end{tabular}


mechanical tensile shear tests were performed before starting the aging and after 4,8 and 12 weeks at the respective aging condition.

\section{Mechanical tensile shear tests}

The mechanical tensile shear tests were performed using a Midi 20-1074x10 (Messphysik Materials Testing GmbH, Fürstenfeld, Austria) universal testing machine with a traverse speed of $0.5 \mathrm{~mm} / \mathrm{min}$. Laminated shear joints were used for testing in order to avoid eccentricity when placed in the jigs of the testing machine and to minimize the bending during the tensile shear tests [15]. For all aging conditions five equivalent samples were tested after the respective aging times.

\section{Results and discussion}

\section{Accelerated laboratory aging tests}

The maximum tensile shear strength in dependence of aging condition and aging time is displayed in Fig. 1.

Figure 1 illustrates that the maximum shear stress decreases significantly at the conditions with high humidity $\left(60^{\circ} \mathrm{C} / 95 \% \mathrm{RH}\right.$ and $\left.80^{\circ} \mathrm{C} / 95 \% \mathrm{RH}\right)$. The slight increase in shear strength observed with samples after 8 weeks of aging at $80{ }^{\circ} \mathrm{C} / 95 \% \mathrm{RH}$ to 12 weeks is assigned to the relaxation of thermal stress caused by curing at $180{ }^{\circ} \mathrm{C}$ and physical aging taking place at temperatures approaching the glass transition temperature. In the case of the reference condition $\left(23^{\circ} \mathrm{C} / 50 \% \mathrm{RH}\right)$ the shear stress remains constant over time.

\section{Development of time-, temperature- and humidity-dependent model function}

In order to develop a model for predicting time-, temperature- and humidity-dependent progression of aging under climatic conditions the commercial software JMP ${ }^{\circledR}$ (SAS Institute Inc., North Carolina, USA) was used. Since only modeling in dependence of one damaging factor for accelerated destructive degradation is possible, the damaging factors were initially modeled separately from each other. Thus, the temperature dependence was modeled by keeping the relative humidity constant and then the absolute humidity was modeled. Assuming a WEIBULL distribution Eq. 1, which contains

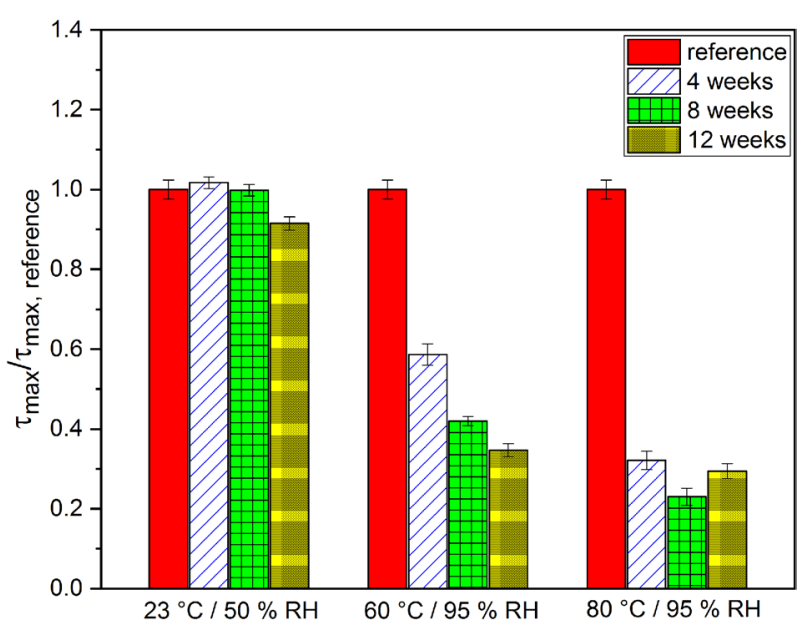

Fig. 1 Maximum tensile shear strength $\tau_{\max }$ in dependence of aging condition and aging time 


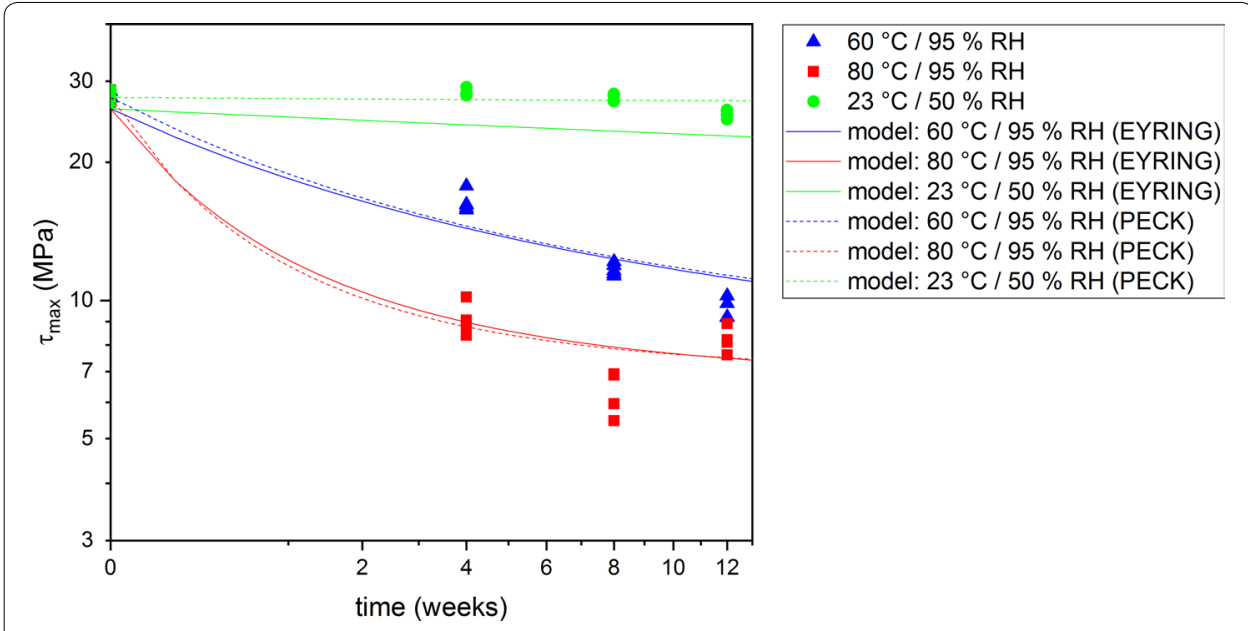

Fig. 2 Maximum tensile shear strength $\tau_{\max }$ (dots) and combined functions to describe the temperature and humidity dependence of the maximum tensile shear strength referring to EYRING (solid line) and PECK (broken line)

an ARRHENIUS term [1], was determined to describe the change in maximum tensile shear stress $\tau_{\max }$ in dependence of temperature $T$ and time.

$$
\begin{aligned}
\log \left(\tau_{\max }(T)\right)= & \exp \left(-0.16+0.53 \cdot \exp \left(-0.02 \cdot \exp \left(0 . 5 1 \cdot \left(\frac{11605}{296.15}\right.\right.\right.\right. \\
& \left.\left.\left.\left.-\frac{11605}{273.15+T}\right)\right) \cdot \sqrt{\text { time }}\right)\right) \cdot 0.97
\end{aligned}
$$

For the function to describe the change in maximum tensile shear stress $\tau_{\max }$ in dependence of the absolute humidity $A H$ and time Eq. 2 was chosen.

$$
\left.\log \left(\tau_{\max }(A H)\right)=\exp \left(0.37+\left(-0.14+0.14 \cdot \exp \left(-\frac{A H}{108}\right)\right) \cdot \sqrt{\text { time }}\right)\right) \cdot 0.98
$$

In literature $[2,8]$ two different procedures are proposed for combining the influences of temperature and humidity in accelerated degradation tests. According to the EYRING model [2] the influences of temperature and relative humidity are linked in the exponential ARRHENIUS term. In contrast the PECK model [8] uses a multiplicative connection of the term for describing the humidity influence and the ARRHENIUS term for describing the temperature dependence. In this study both approaches were examined. Referring to EYRING's model Eq. 3 was obtained to describe the maximum tensile shear stress $\tau_{\max }$ in dependence of temperature, absolute humidity $A H$ and time.

$$
\begin{aligned}
\log \left(\tau_{\max }(T, A H)\right)_{E Y}= & \exp (-0.16+0.53 \cdot \exp (-0.02 \\
& \cdot \exp \left(0.51 \cdot\left(\frac{11605}{296.15}-\frac{11605}{273.15+T}\right)\right) \\
& \left.\left.\cdot\left(-0.14+0.14 \cdot \exp \left(-\frac{A H}{108}\right)\right) \cdot 0.98 \cdot \sqrt{\text { time }}\right)\right) \cdot 0.97
\end{aligned}
$$




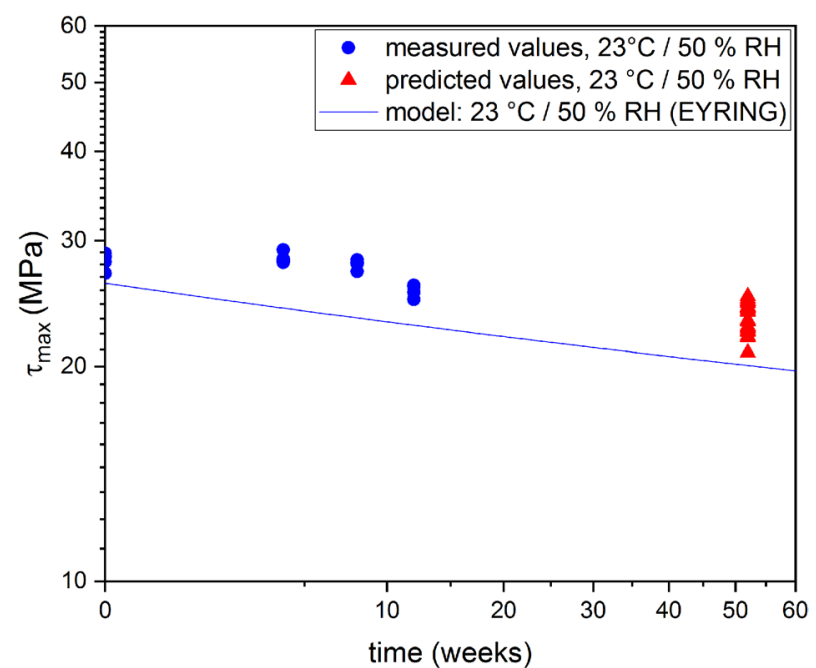

Fig. 3 Measured maximum tensile shear strength $\tau_{\max }$ (circles), model function based on EYRING (line) and predicted values at the time of 52 (triangles) for $23^{\circ} \mathrm{C}, 50 \% \mathrm{RH}$

Likewise, referring to PECK's model the functions to describe the temperature and humidity dependence are combined as follows:

$$
\begin{aligned}
\log \left(\tau_{\max }(T, A H)\right)_{P}= & \left(\exp \left(0.37+\left(-0.14+0.14 \cdot \exp \left(-\frac{A H}{108}\right)\right) \cdot \sqrt{\text { time }}\right) \cdot 0.98\right)^{m} \\
& \cdot \exp \left(-0.16+0.53 \cdot \exp \left(-0.02 \cdot \exp \left(0.51 \cdot\left(\frac{11605}{296.15}-\frac{11605}{273.15+T}\right)\right) \cdot \sqrt{\text { time }}\right)\right) \cdot 0.97
\end{aligned}
$$

The empirical constant $m$ is calculated to be 0.08 by non-linear regression analysis with JMP ${ }^{\circledR}$ software (SAS Institute Inc., North Carolina, USA).

The combined functions based on EYRING and PECK and their ability to describe the change of the measure maximum tensile shear strength values are displayed in Fig. 2.

Figure 2 illustrates that both the PECK model as well as the EYRING model describe the measured values quite good. They are very similar to each other for describing the change in maximum tensile shear strength for $60{ }^{\circ} \mathrm{C} / 95 \% \mathrm{RH}$ and $80{ }^{\circ} \mathrm{C} / 95 \% \mathrm{RH}$. A significant difference is observed in describing the experimental data for $23^{\circ} \mathrm{C} / 50 \% \mathrm{RH}$. The EYRING model is more conservative than the PECK model which is why the following saftey prediction was based on the EYRING model.

\section{Safety prediction for reference condition}

In order to predict the failure probability for the reference condition all experimental data of this condition were mathematically shifted in constant distance along the corresponding model line to a freely selectable future point in time. In this study 52 weeks were set exemplarily (Fig. 3). The shifting of the data in constant distance along the model line is based on the assumption that specimes which show a comparatively high tensile shear strength in the observation period will also show a comparatively high tensile shear strength at any future point in time. The respective assumption applies 


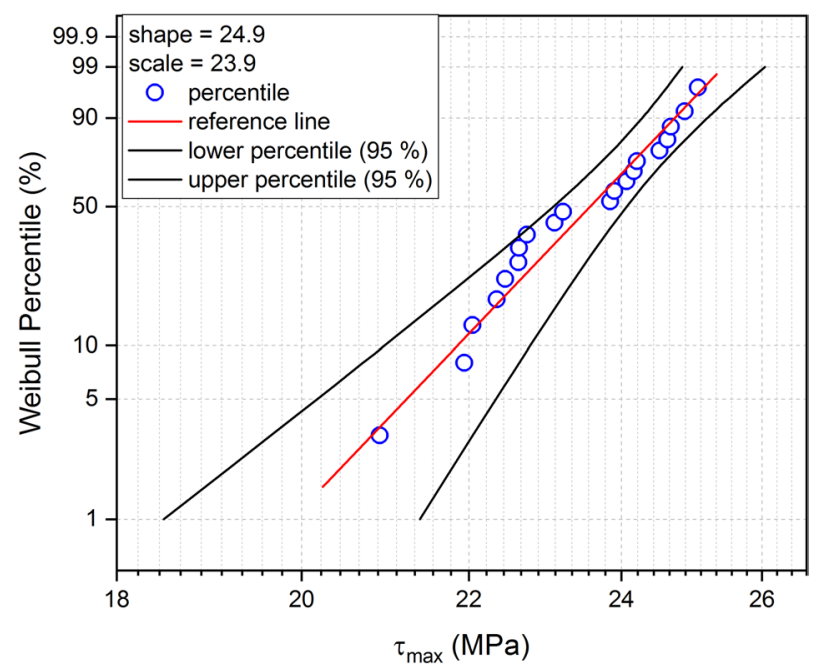

Fig. 4 WEIBULL probability plot of $23^{\circ} \mathrm{C}, 50 \% \mathrm{RH}$ with predicted values for the maximum tensile shear strength after 52 weeks

to specimens which show a comparatively low tensile shear strength. Based on these assumptions it is possible to include all experimental data to do a safety prediction for a certain condition considering a reliable variance.

The predicted values for the maximum tensile shear strength after 52 weeks are plotted in a WEIBULL probability plot (Fig. 4).

Figure 4 illustrates that the predicted values are WEIBULL-distributed within the 95\% confidence interval. For a given failure limit which is dependent on the specific case of application, the probability of failure is evident from the WEIBULL probability plot. If the failure limit is for example defined as $22 \mathrm{MPa}$ the failure probability after 52 weeks at $23{ }^{\circ} \mathrm{C}, 50 \% \mathrm{RH}$ would be approximately $10 \%$. Furthermore it is possible to calculate the factor of safety $\beta$ [17] with the WEIBULL parameters given from the WEIBULL probability plot for a certain load.

\section{Conclusion}

In this study accelerated destructive degradation tests for tensile shear specimen were performed at three different aging conditions. As reference condition $23{ }^{\circ} \mathrm{C} / 50 \% \mathrm{RH}$ was used. The maximum tensile shear strength was used to characterize the aging and was modeled with combined functions of temperature and humidity referring to the EYRING model and the PECK model respectively. It became apparent that the EYRING model fits the experimental data in a more conservative manner. This is why the model function based on EYRING was used to predict safety for the reference condition.

Authors' contributions

KG analyzed and interpreted the data, did the computer-based extrapolation and was major contributor in writing the manuscript. PLG made substantial contributions to analysis and interpretation of the data and has been involved in revising the manuscript critically. Both authors read and approved the final manuscript. 


\section{Acknowledgements}

The authors kindly acknowledge funding by the Research Association for Steel Application FOSTA with grants from the Federal Ministry for Economic Affairs and Energy. The authors would also like to kindly acknowledge support provided by the Advanced Materials Engineering (AME) and High Performance Composite Constructions (HiPerCon) priority research activity of Rhineland-Palatinate.

\section{Competing interests}

The authors declare that they have no competing interests.

\section{Availability of data and materials}

The datasets used and analyzed during this current study are available from the corresponding author on reasonable request.

\section{Funding}

The research was funded by the Research Association for Steel Application FOSTA with grants from the Federal Ministry for Economic Affairs and Energy.

\section{Publisher's Note}

Springer Nature remains neutral with regard to jurisdictional claims in published maps and institutional affiliations.

Received: 20 September 2018 Accepted: 27 October 2018

Published online: 02 November 2018

\section{References}

1. Laidler KJ. The development of the Arrhenius equation. J Chem Educ. 1984;61(6):494-8.

2. Escobar LA, Meeker WQ. A review of acceleated test models. Stat Sci. 2006;21(4):552-77. https://doi.org/10.1214/08834 2306000000321

3. Gladstone $S$, Laidler KJ, Eyring $H$. The theory of rate processes. 1st ed. New York: McGraw-Hill Book Co.; 1941.

4. Eyring H, Lin SH, Lin SM. Basic chemical kinetics. 1st ed. New York: John Wiley \& Sons Inc; 1980.

5. Hartzell AL, da Silva MG, Shea HR. MEMS Reliability. 1st ed. New York: Springer; 2011.

6. Matting A. Metallkleben: Grundlagen Technologie Prüfung Verhalten Berechnung Anwendungen. Berlin: Springer; 1969.

7. Kececioglu D. Reliability \& life testing handbook. 2nd ed. Lancaster: DEStech Publication Inc.; 2002.

8. Peck SD (2007) Comprehensive model for humidity testing correlation. In: Proceedings of the 24th international reliability physics symposium, Anaheim, USA; Apr 1-3 1986. New York: IEEE. https://doi.org/10.1109/irps.1986.362110.

9. Dow Automotive. Technical datasheet-Betamate 1496V; 2007.

10. Voestalpine Steel Division. Dual-phase steels data sheet; 2017.

11. CEN European Committee for Standardization. DIN EN ISO 527-1:2012-06. Plastics - determination of tensile properties - Part 1: General principles (ISO 527-1:2012). German version EN ISO 527-1:2012. Brussels; 2012.

12. CEN European Committee for Standardization. DIN EN ISO 6721-1:2011-08. Plastics - determination of dynamic mechanical properties - Part 1: General principles (ISO 6721-1:2011). German version EN ISO 6721-1:2011. Brussels; 2012

13. CEN European Committee for Standardization. DIN EN 10346:2015-10. Continuously hot-dip coated steel flat products for cold forming - Technical delivery conditions. German version EN 10346:2015. Brussels; 2015.

14. CEN European Committee for Standardization. DIN EN 10338:2015-10. Hot rolled and cold rolled non-coated products of multiphase steels for cold forming - Technical delivery conditions. German version EN 10338:2015. Brussels; 2015.

15. da Silva LFM, Carbas RJC, Banea MD. Failure Strength Tests. In: da Silva L, Öchsner A, Adams R, editors. Handbook of adhesion technology. 2nd ed. Cham: Springer; 2017.

16. Escobar LA, Meeker WQ, Kugler DL, Kramer LL. Accelerated destructive degradation tests: data, models and analysis. In: Lindqvist BH, Doksum KA, editors. Mathematical and statistical methods in reliability. River Edge: World Publishing Company; 2003.

17. CEN European Committee for Standardization. DIN EN 119:2010-12. Eurocode - Basis of structural design. German version EN 1990:2002 + A1:2005 + A1:2005/AC:2010. Brussels; 2010.

\section{Submit your manuscript to a SpringerOpen ${ }^{\circ}$ journal and benefit from:}

- Convenient online submission

Rigorous peer review

- Open access: articles freely available online

- High visibility within the field

Retaining the copyright to your article

Submit your next manuscript at $>$ springeropen.com 